\title{
Triphenylene based metal-pyridine cages
}

\author{
Giacomo Berton ${ }^{a}$, Tommaso Lorenzetto ${ }^{a}$, Giuseppe Borsato ${ }^{a}$, Paolo Sgarbossa ${ }^{b}$, \\ Claudio Santo ${ }^{\mathrm{a}}$, Fabiano Visentin ${ }^{\mathrm{a}}$, Fabrizio Fabris ${ }^{\mathrm{a}}$, Alessandro Scarso ${ }^{\mathrm{a}, *}$ \\ a Dipartimento di Scienze Molecolari e Nanosistemi, Università Ca' Foscari di Venezia, Via Torino 155, 30172 Venezia Mestre, Italy \\ ${ }^{\mathrm{b}}$ Dipartimento di Ingegneria Industriale, Università degli Studi di Padova, via Marzolo 9, 35131 Padova, Italy
}

\section{A R T I C L E I N F O}

Article history:

Received 27 July 2019

Revised 16 September 2019

Accepted 23 September 2019

Available online 23 September 2019

\section{Keywords:}

Triphenylene

Coordination cage

Palladium

Platinum

Supramolecular chemistry

Exchange process

$\mathrm{C}_{3}$-symmetry

\begin{abstract}
A B S T R A C T
$C_{3}$-symmetric pyridine containing tris-benzyl-O-substituted hexahydroxytriphenylene derivatives were prepared and used in combination with square-planar $\mathrm{Pd}(\mathrm{II})$ and $\mathrm{Pt}(\mathrm{II})$ complexes for the self-assembly of molecular cages in solution. The formation of a trigonal bipyramid $\mathrm{M}_{3} \mathrm{~L}_{2}$ cage was demonstrated by multinuclear NMR analyses and pseudo 2D DOSY experiments and supported by semi-empirical calculations.
\end{abstract}

(c) 2019 Elsevier Ltd. All rights reserved.

\section{Introduction}

Metal-ligand self-assembled cages [1-3] are very promising host systems [4] characterized by unique features and properties in the field of supramolecular recognition [5,6], being able in some cases to stabilize highly reactive molecular structures [7,8], with future potential biomedical applications $[9,10]$. As container molecules, they feature internal cavities that can bind multiple guests [11], acting as supramolecular catalysts or nanoreactors [12,13] and in some cases promoting regio- and stereoselective transformations [14]. In particular, are the tetrahedral capsules developed by the group of Raymond [15] based on catechol units connected through $\mathrm{Ga}$ (III) metal corners that can stabilize cationic intermediates which have been applied in a series of organic transformations with accelerations of up to more than two million-fold with respect to the uncatalyzed reaction [16].

Other landmark examples were reported by the group of Fujita, based on tris-pyridyl units connected with Pd(II) corners leading to water soluble cavitand or capsule hosts [17]. Larger supramolecular cages were introduced by Fujita [18] and developed by Reek [19] as nanoreactors with the ability to provide multiple catalytic sites within the cavity of the coordination cages. The groups of Nitschke [20] and Ward [21] further extended the field with a ser-

\footnotetext{
* Corresponding author.

E-mail address: alesca@unive.it (A. Scarso).
}

ies of metal-ligand boxes and tetrahedral assemblies able to bind multiple guests for a wide range of applications. As far as the organic polydentate units are concerned, the most common units are based on large flat aromatic surfaces, such as porphyrins [22], banana-shaped units [23], or several other scaffolds often endowed with pyridine terminal units [24].

With the aim of widening the range of organic scaffolds which can be combined with metal corners for the development of new supramolecular host systems characterized by new shapes, sizes and molecular recognition properties, we recently developed a new efficient procedure to convert hexahydroxytriphenylene $\mathbf{1}$ into the $C_{3}$-symmetric derivative $\mathbf{2}$. Furthermore, the unsubstituted $\mathrm{OH}$ moieties of $\mathbf{2}$ have been converted through a Mannich reaction into a series of elaborated $C_{3}$-symmetric triphenylenic scaffolds, endowed with three identical units (3, Scheme 1) [25].

In this contribution, we report the synthesis of a series of $C_{3}$-symmetric triphenylene polydentate scaffolds bearing three pyridine units connected in position 2,3 and $4(\boldsymbol{o}-\mathbf{3}, \boldsymbol{m}-\mathbf{3}, \boldsymbol{p}-\mathbf{3}$, Scheme 1) and their interaction with soft Lewis metal centers for the development of new supramolecular $\mathrm{M}_{3} \mathrm{~L}_{2}$ capsules in organic media [26]. The formation of the metal-ligand assemblies by interaction with $\left[(\mathrm{dppp}) \mathrm{Pd}(\mathrm{OTf})_{2}\right]$ (dppp = 1,3-bis-diphenylphosphinopropane), $\quad\left[(\mathrm{dppe}) \mathrm{Pd}(\mathrm{OTf})_{2}\right] \quad$ (dppe $=1,2$-bis-diphenylphosphinoethane) and [(dppp) Pt(OTf $\left.)_{2}\right]$ was monitored by ${ }^{1} \mathrm{H},{ }^{31} \mathrm{P},{ }^{19} \mathrm{~F}$ NMR, and pseudo 2D-DOSY NMR spectroscopy. Further experiments allowed us to suggest that the $\boldsymbol{m} \mathbf{- 3}$ substituted polydentate ligand 
<smiles>Oc1cc2c3cc(O)c(O)cc3c3cc(O)c(O)cc3c2cc1O</smiles>

1<smiles>Oc1ccc2c(c1)c1cc(OCc3ccccc3)c(O)cc1c1cc(OCc3ccccc3)c(O)cc21</smiles>

2<smiles>[R]N1COc2c(OCc3ccccc3)cc3c(c2C1)c1cc(OCc2ccccc2)c2c(c1c1cc(OCc4ccccc4)c4c(c31)CN([R])CO4)CN([R])CO2</smiles>
or aryls

3<smiles>Cc1ccccn1</smiles><smiles>Cc1ccncc1</smiles>

0-3 $m-3$<smiles>CC(C)(C)c1ccncc1</smiles>
$p-3$

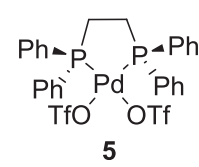

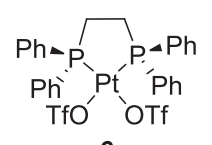

6

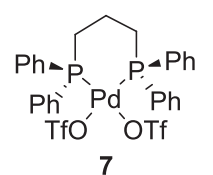

Scheme 1. Structures of hexahydroxytriphenylene 1, the $C_{3}$-symmetric tris-benzyl derivative 2, the tris-substituted $C_{3}$-symmetric Mannich products 3 and $\mathrm{Pd}(\mathrm{II})$ and $\mathrm{Pt}(\mathrm{II})$ metal complexes for the formation of the coordination cages in solution.

in solution with square planar metal complexes afford coordination cages characterized by a $\mathrm{M}_{3} \mathrm{~L}_{2}$ stoichiometry. Because of the large number of possible variables in these flexible polydentate ligands, many possible isomers can be postulated. Quantomechanical calculations supported the hypothesis that many isomers are in equilibrium in solution due to their similar energies. Due to the flexibility of the assemblies formed, no clear host-guest properties were disclosed, albeit binding of solvent molecules or more probably of counter-anions cannot be ruled out. Due to the general use of the term cages for metal-ligand assemblies characterized by different size, shape and not specifically showing binding of guests $[2,23,27]$, from here on we will call the assemblies investigated as cages.

\section{Results and discussion}

With the aim to synthesise the series of tris-pyridine containing ligands 3, we first investigated the one-pot reaction between $C_{3}-2$ with para-formaldehyde in the presence of $o-, m$ - or $p$-aminopyridine. In all cases, the reaction led to the formation of complex mixtures of products. Therefore, we revised the syntheses by initially preparing the single hemiaminal reagent by reaction of the aminopyridine with paraformaldehyde in $n$-butanol in the presence of a catalytic amount of acetic acid for $18 \mathrm{~h}$ (Scheme 2).

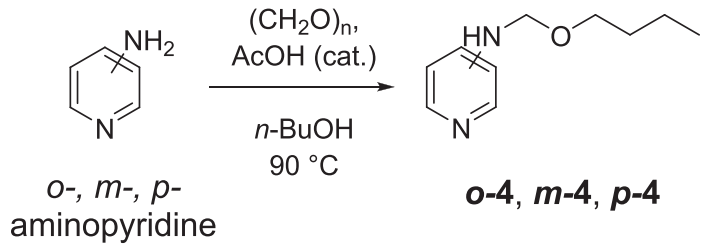

Scheme 2. In situ synthesis of the hemiaminals $\boldsymbol{o -}, \boldsymbol{m}$ - and $\boldsymbol{p}-\mathbf{4}$ from $o-, m$ - and $p$ aminopyridine.

Afterwards, the excess of $n$-butanol was removed under vacuum and products $\boldsymbol{o}, \boldsymbol{m}, \boldsymbol{p}-\mathbf{4}$ were reacted directly without further purification with $\mathbf{2}$ in the presence of additional paraformaldehyde in a more suitable solvent. The reactions were carried out in a sealed screw-cap Pyrex test tube in order to avoid paraformaldehyde loss by sublimation. The three reactions with the different hemiaminals required different reaction times to achieve complete conversion of $\mathbf{2}$, as reported in Scheme 3, due to their different reactivities. In detail, the reaction of 0 -aminopyridine $\mathbf{o - 4}$ took $24 \mathrm{~h}$ at $100^{\circ} \mathrm{C}$, while for $p$-aminopyridine $\boldsymbol{p}$-4 the reaction time was doubled to $48 \mathrm{~h}$. The least reactive $m$-aminopyridine derivative $\boldsymbol{m}-\mathbf{4}$ required the most severe reaction conditions: the mixture was heated at $110^{\circ} \mathrm{C}$ for $48 \mathrm{~h}$. The products $\mathbf{0 , m}, \mathbf{p}-\mathbf{3}$ were then isolated by precipitation, in moderate to good yields (o-3 90\%, $\boldsymbol{m}-\mathbf{3}$ $86 \%$ and $\boldsymbol{p}-3$ 75\%) showing symmetrical ${ }^{1} \mathrm{H}$ and ${ }^{13} \mathrm{C}$ NMR spectra in agreement with the proposed structures (see ESI).

In order to investigate the interaction between the three trispyridine ligands and transition metal centers for the preparation of molecular cages, we prepared a series of Pd(II) and Pt(II) diphosphine complexes bearing two labile triflate ligands, that can be efficiently displaced by pyridine in solution. Two $\mathrm{Pd}(\mathrm{II})$ complexes with 1,2-diphenylphosphino ethane $\left[\operatorname{Pd}(\mathrm{dppe})(\mathrm{OTf})_{2}\right] \mathbf{5}$ and 1,3diphenylphosphino propane $\left[\mathrm{Pd}(\mathrm{dppp})(\mathrm{OTf})_{2}\right] 7$ were prepared fol-

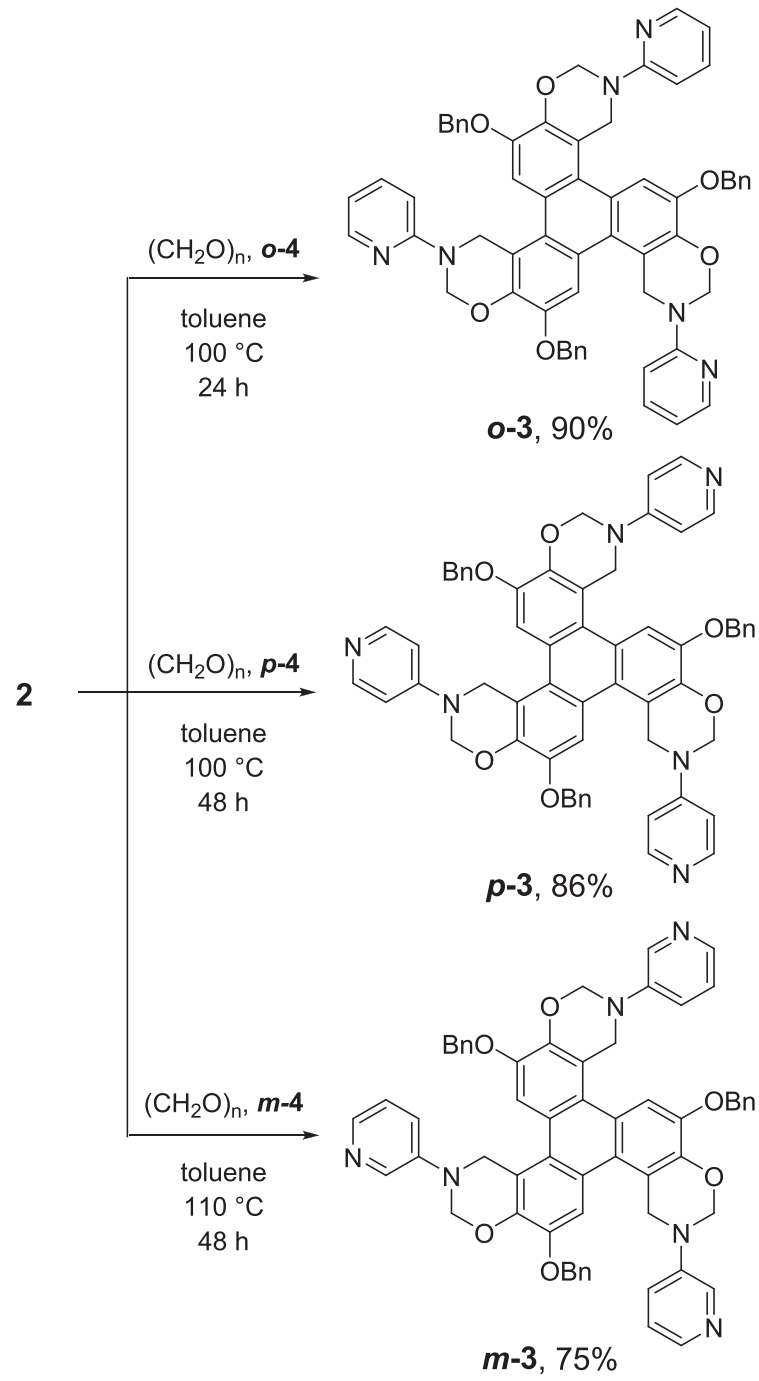

Scheme 3. Synthesis of the three tris-pyridine containing ligands $\mathbf{3}$ via the reaction of $\mathbf{2}$ with the three hemiaminals $\boldsymbol{o -}, \boldsymbol{m}$ - and $\boldsymbol{p}-\mathbf{4}$ from $o-, m$ - and $p$-aminopyridine. 
lowing known procedures [28,29], as well as the Pt(II) complex bearing the dppe ligand $\left[\mathrm{Pt}(\mathrm{dppe})(\mathrm{OTf})_{2}\right] \mathbf{6}$, to investigate the well-known effect of the lower exchange rate of ligands that characterizes Pt(II) complexes with respect to $\mathrm{Pd}(\mathrm{II})$ analogues.

The interaction between the polydentate ligands and the metal complexes was investigated by undertaking a series of titration experiments during which the ${ }^{1} \mathrm{H},{ }^{31} \mathrm{P}$ and ${ }^{19} \mathrm{~F}$ NMR spectra were recorded to monitor the formation of coordination complexes, following the resonances of 3 with ${ }^{1} \mathrm{H}$ NMR, the resonances of the diphosphino ligands directly coordinated to the metal with ${ }^{31} \mathrm{P}$ NMR and the triflate anions that are displaced by the incoming pyridine units with ${ }^{19} \mathrm{~F}$ NMR. The NMR experiments were carried out by titrating a $5 \mathrm{mM}$ solution of 3 in $\mathrm{CD}_{2} \mathrm{Cl}_{2}$ with a $25 \mathrm{mM}(\mathbf{5})$ or $12.5 \mathrm{mM}$ solution ( 6 and 7 ) of the metal complex in the same solvent.

The titration experiment between $\mathbf{0 - 3}$ and $\mathbf{5}$ showed, even after 0.2 equivalents of the metal complex with respect to the triphenylene ligand, broadening of the resonances of the aromatic scaffold, with a clear down-field shift, particularly for the resonances of the pyridine residues (Fig. 1). After reaching a 1:1 ratio between the metal and ligand, the resonances were too broad to be unequivocally assigned. No new resonances were observed ascribable to decomposition pathways, indicating the high stability of the triphenylene ligand in the presence of the metal center. The broadening of the resonances is likely to be due to exchange processes, occurring between different metal centers and the coordinating pyridine units.

The ${ }^{31} \mathrm{P}$ NMR spectra recorded during the titration were also not suitable to clearly follow the process (see ESI, Titration 1). In contrast, the ${ }^{19} \mathrm{~F}$ NMR spectra turned out to be more sensitive, observing the gradual de-shielding of the resonance of the triflate anion during the titration, until a maximum value corresponding to a molar fraction of 0.4 (Fig. 2). The latter value corresponds to a 2:3 ligand-to-metal ratio that is in agreement with the formation of metal-ligand cages with a $\mathrm{M}_{3} \mathrm{~L}_{2}$ stoichiometry between $\boldsymbol{o - 3 -}$ and 5 .

A similar behavior of the NMR spectra was observed for the titration between $\boldsymbol{p}$-3 and $\mathbf{5}$, with a rapid broadening of the ${ }^{1} \mathrm{H}$ NMR resonances and down-field shifting of the ${ }^{19} \mathrm{~F}$ NMR resonances of the triflate anion. Moreover, after the addition of 1.0 equivalent of $\mathbf{5}$ with respect to the triphenylene ligand, precipitation was observed, which hampered the continuation of the titration experiments due to the formation of poorly soluble metalligand aggregates, likely attributed to coordination polymers (see ESI, Titration 2).

The titration experiment with the $\boldsymbol{m}-\mathbf{3}$ ligand turned out to be the most informative, since no precipitation was observed. Similarly, the ${ }^{1} \mathrm{H}$ NMR spectra showed rapid broadening of the resonances (Fig. 3), while the ${ }^{19} \mathrm{~F}$ NMR spectra showed a clear-cut

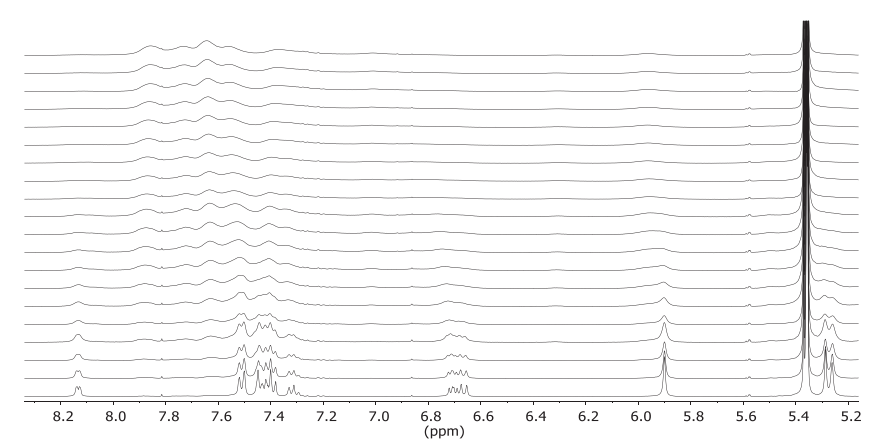

Fig. 1. ${ }^{1} \mathrm{H}$ NMR spectra for the titration of the triphenylene polydentate ligand $\boldsymbol{o}-\mathbf{3}$ with 5 (from bottom to top each spectrum corresponds to 0.10 eq. of metal with respect to the ligand).

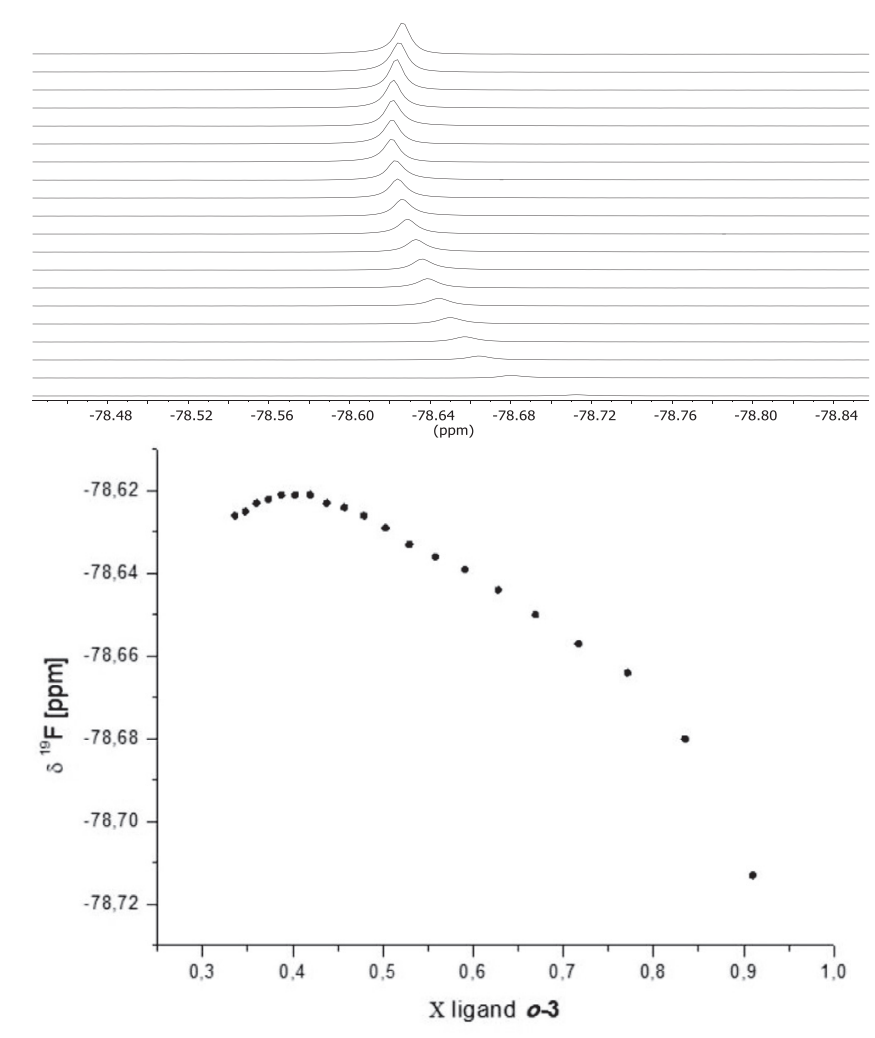

Fig. 2. ${ }^{19}$ F NMR spectra during the titration of $\boldsymbol{o}-\mathbf{3}$ with increasing amounts of $\mathbf{5}$ (each spectrum after 0.1 eq. of metal complex) (top); plot of the ${ }^{19} \mathrm{~F}$ NMR chemical shift of the triflate anion vs the molar fraction of ligand (bottom).

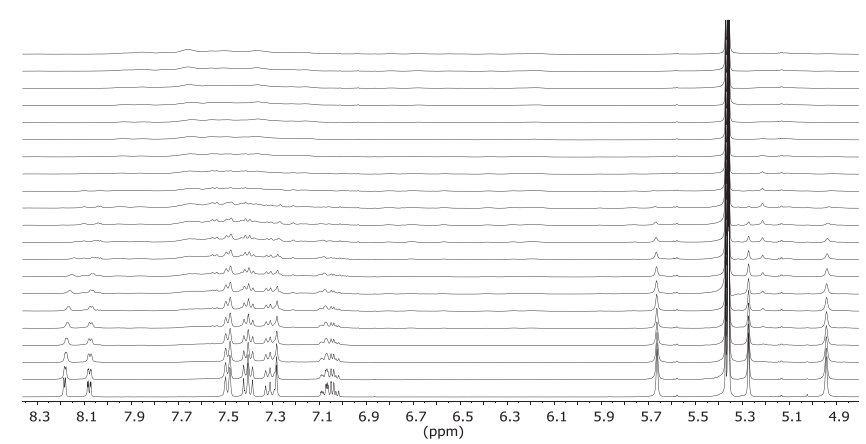

Fig. 3. ${ }^{1} \mathrm{H}$ NMR spectra for the titration of the triphenylene polydentate ligand $\boldsymbol{m}-\mathbf{3}$ with 5 (from bottom to top each spectrum corresponds to 0.1 eq. of metal with respect to the ligand).

change of chemical shift for the triflate anion corresponding to a molar ratio 0.4 between the ligand and metal (Fig. 4), in accordance with the formation in solution of a well-defined $\mathrm{M}_{3} \mathrm{~L}_{2}$ coordination species.

In order to try to observe clearer resonances in the ${ }^{1} \mathrm{H}$ NMR spectra for the interaction between $\boldsymbol{m}-\mathbf{3}$ and $\mathbf{5}$, we recorded the spectra in $\mathrm{CD}_{3} \mathrm{CN}$ for the $\mathrm{M}_{3} \mathrm{~L}_{2}$ assembly at $302 \mathrm{~K}, 332 \mathrm{~K}$ and $347 \mathrm{~K}$ (Fig. 5). The spectrum at $302 \mathrm{~K}$ was very broad and an increase of the temperature to $332 \mathrm{~K}$ led to the observation of selected resonances, that further sharpened at $347 \mathrm{~K}$, revealing the doublet attributed to the proton in the ortho position with respect to the $\mathrm{N}$ atom of the pyridine units. Furthermore, the observation of a single resonance for the benzyl methylene units indicated a rather fast exchange on the NMR timescale at that temperature, suggesting the presence of a major species in solution. The spectra recorded again at room temperature corresponded to 

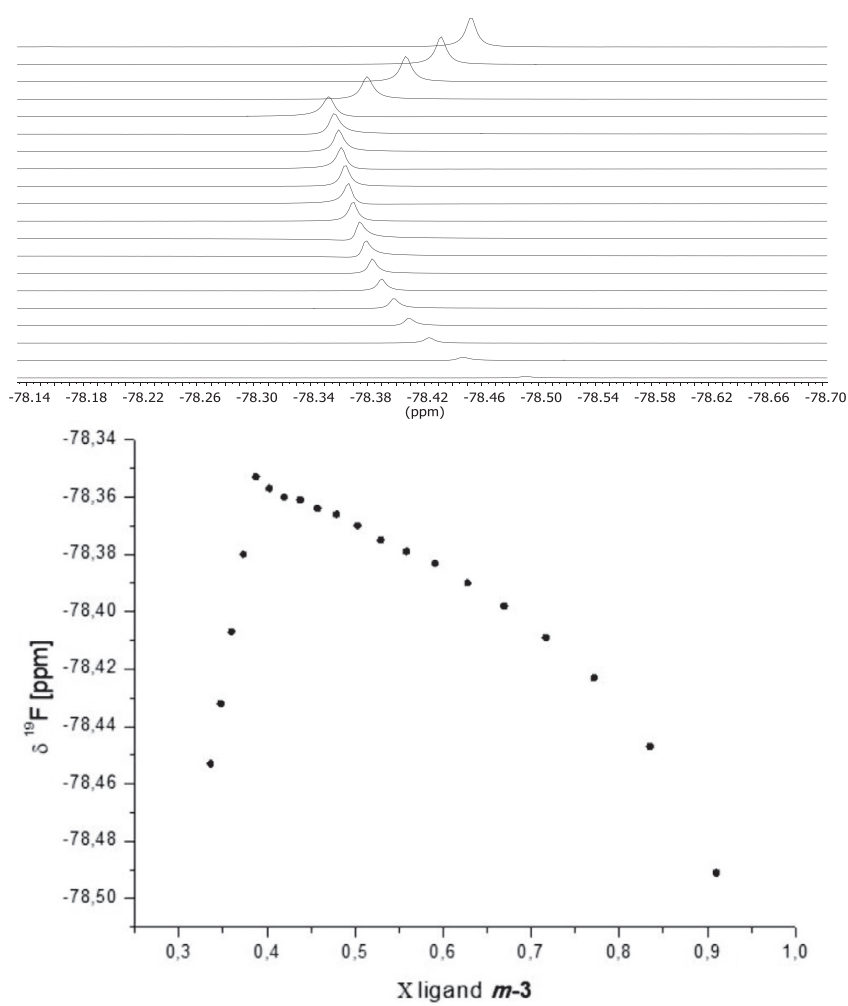

Fig. 4. ${ }^{19} \mathrm{~F}$ NMR spectra during the titration of $\boldsymbol{m}-\mathbf{3}$ with increasing amounts of $\mathbf{5}$ (each spectrum after 0.1 eq. of metal complex) (top); plot of the ${ }^{19} \mathrm{~F}$ NMR chemical shift of the triflate anion $v s$ the molar fraction of ligand (bottom).
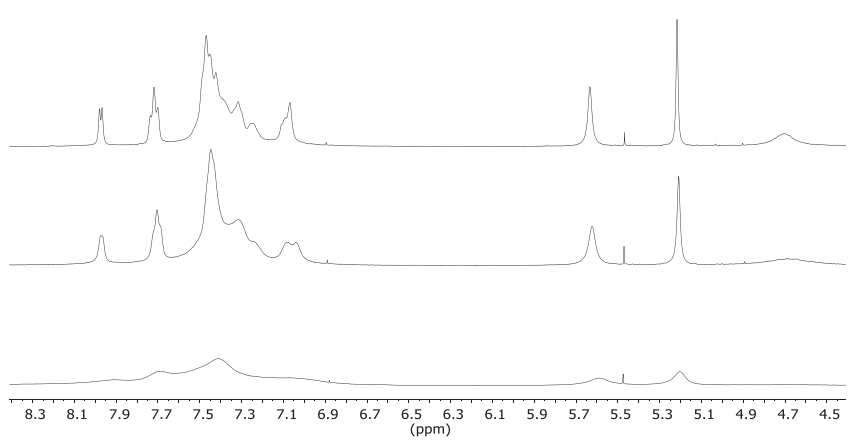

Fig. 5. ${ }^{1} \mathrm{H}$ NMR spectra of 5 with $\boldsymbol{m}$-3 in a $\mathrm{M}_{3} \mathrm{~L}_{2}$ ratio in $\mathrm{CD}_{3} \mathrm{CN}$ at $347 \mathrm{~K}, 332 \mathrm{~K}$ and $302 \mathrm{~K}$ (from top to bottom).

the original spectrum, indicating that the system is stable and reversible in the range of temperatures investigated.

The exchange process that involves the metal-ligand assemblies in solution could also be explained by considering that two molecules of 3, facing each other through coordination with the metal, form two diastereomeric assemblies, due to the combination of the two enantiotopic faces of triphenylene 3. Therefore, two possible diastereoisomers $\mathrm{M}_{3} \mathrm{~L}_{2}$ are possible: one $C_{3}$-symmetric between homochiral ligands (as a racemate) and the $C_{3 \mathrm{~h}}$-symmetric meso with heterochiral ligands, thus causing the doubling of all resonances (Scheme 4).

To further investigate the formation of the coordination cage in solution, a series of pseudo 2D-DOSY NMR spectra were recorded for the free ligand $\boldsymbol{m}-\mathbf{3}$, the free complex $\mathbf{5}$ and the $\mathrm{M}_{3} \mathrm{~L}_{2}$ assembly in $\mathrm{CD}_{2} \mathrm{Cl}_{2}$ solution at $300 \mathrm{~K}$ (Fig. 6). The comparison between these experiments showed that the diffusion coefficient in solution of the metal complex $\mathbf{5}$ is larger than the free triphenylene $\boldsymbol{m} \mathbf{- 3}$, which is

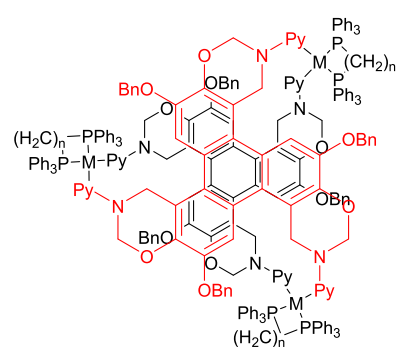

homochiral

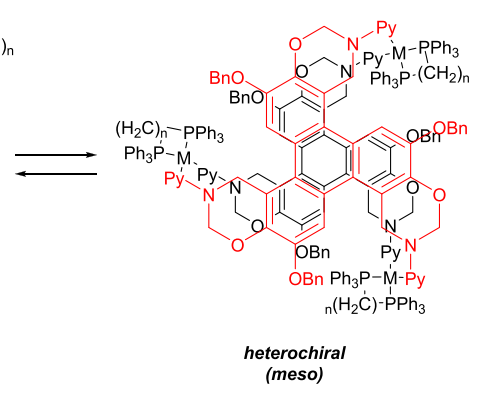

Scheme 4. Heterochiral meso and homochiral racemic $\mathrm{M}_{3} \mathrm{~L}_{2}$ assemblies obtained from the achiral 3 triphenylene pyridine ligands.

an expected result, considering the smaller size of the former and its more spherical shape. When $\mathbf{5}$ and $\boldsymbol{m}-\mathbf{3}$ were both present in a 3:2 M ratio, two effects can be highlighted: 1 ) the diffusion coefficient of both species is identical; 2) the common diffusion coefficient is lower than both the two corresponding free species, which is a strong indication of the formation of a new coordination species. Based on the flat non-spherical shape of the ligand and the similar but thicker shape of the expected $\mathrm{M}_{3} \mathrm{~L}_{2}$ assembly, the decrease of the diffusion coefficient observed agrees with the possible formation of a trigonal bipyramidal cage. Considering the broadening of the resonances of the coordination species, which is an indication of an ongoing exchange process, it was not possible to extrapolate an indication of the MW of the aggregate in solution [30]. Nevertheless, the value of the diffusion coefficient is not drastically different with respect to that of the single triphenylene ligand $\boldsymbol{m}-\mathbf{3}$ in solution, thus excluding the formation of polymeric assemblies and of very large aggregates characterized by the same $\mathrm{M}_{3} \mathrm{~L}_{2}$ stoichiometry but eventually composed of multiple of these units.

The triphenylene ligand $\boldsymbol{m}-\mathbf{3}$ was also investigated with other metal corners, such as [Pt(dppe)(OTf $\left.)_{2}\right] \mathbf{6}$, in order to investigate the effect of the different metal center characterized by a generally lower rate of exchange of the ligands. The titration of $\boldsymbol{m}-\mathbf{3}$ with $\mathbf{6}$ was monitored by multinuclear NMR experiments, showing a series of spectra which were very similar to those observed for the metal complex 5. ${ }^{19} \mathrm{~F}$ NMR spectroscopy was again the most efficient experiment to determine the stoichiometry of the assembly, observing a drastic change in chemical shift for the triflate anion when a 0.4 ligand molar fraction was reached, corresponding to the formation of a cage with $\mathrm{M}_{3} \mathrm{~L}_{2}$ stoichiometry (see ESI, Titration 4). We also investigated the effect of the temperature on the NMR spectra, either in $\mathrm{CD}_{3} \mathrm{CN}$ at $300 \mathrm{~K}$ and $348 \mathrm{~K}$ or in $\mathrm{CD}_{2} \mathrm{Cl}_{2}$ at $193 \mathrm{~K}$ and $233 \mathrm{~K}$, observing in all cases complicated spectra (see ESI). In particular, only at high temperature in $\mathrm{CD}_{3} \mathrm{CN}$ were the resonances of the assembly slightly sharper, even though the number of resonances was high. The pseudo 2D-DOSY NMR spectra of the $\mathrm{M}_{3} \mathrm{~L}_{2}$ assembly in $\mathrm{CD}_{3} \mathrm{CN}$ at $348 \mathrm{~K}$, reported in Fig. 7, shows how the signals of the ligand and $\boldsymbol{m}-\mathbf{3}$ and $\mathbf{5}$ have the same diffusion coefficient at high temperature.

The interaction between $\boldsymbol{m}-\mathbf{3}$ and the $\left[\mathrm{Pd}(\mathrm{dppp})(\mathrm{OTf})_{2}\right] \mathbf{7}$ was considered to investigate the effect of a larger bite angle on the $\mathrm{Pd}(\mathrm{II})$ corners. The results of the titration are reported in the ESI (Titration 5), from which in this case the ${ }^{19} \mathrm{~F}$ NMR experiments suggest a $1: 1$ ratio between the tridentate ligand and the metal. The pseudo-2D-DOSY experiments with this combination of metal complex and ligand supported the formation of polymeric aggregates in solution rather than a discrete $M_{3} L_{2}$ cage, due to the observation of very broad cross-peaks in the DOSY spectrum, corresponding to a rather small and uncertain diffusion coefficient for the 1:1 mixture of $\mathbf{7}$ and $\boldsymbol{m} \mathbf{- 3}$. The comparison of this diffusion coefficient with that of the free triphenylene ligand $\boldsymbol{m}-\mathbf{3}$ suggested 


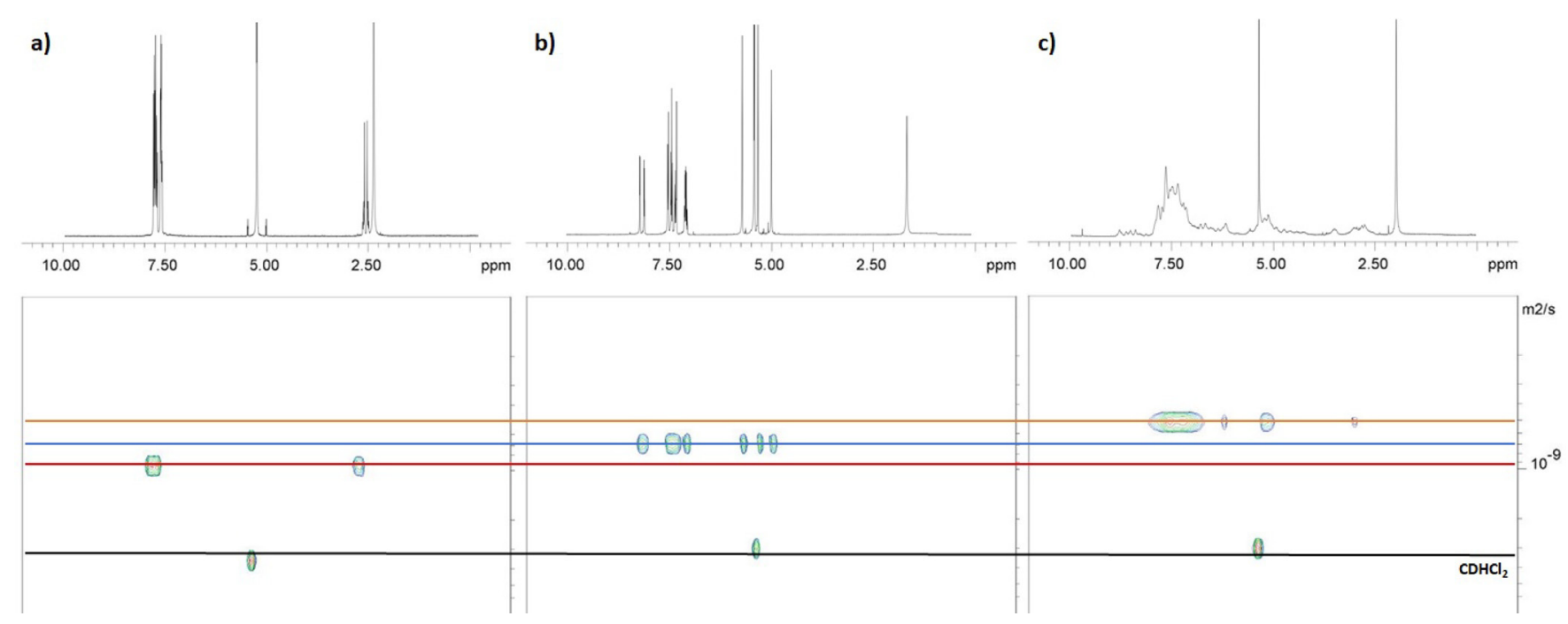

Fig. 6. Pseudo-2D DOSY NMR spectra of a) $\mathbf{5}$, b) tris-pyridine triphenylene ligand $\boldsymbol{m}-\mathbf{3}$ and c) a $\mathrm{M}_{3} \mathrm{~L}_{2}$ combination of $\mathbf{5}$ and $\boldsymbol{m}-\mathbf{3}$ in $\mathrm{CD}_{2} \mathrm{Cl}_{2}$ at $300 \mathrm{~K}$.

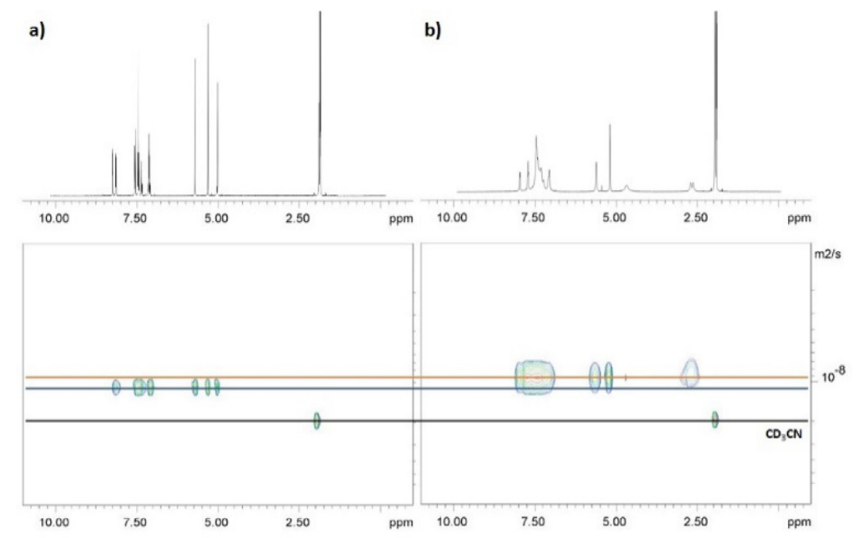

Fig. 7. Pseudo-2D DOSY NMR spectra of a) $\boldsymbol{m}-\mathbf{3}$ and b) a $\mathrm{M}_{3} \mathrm{~L}_{2}$ combination of $\mathbf{5}$ and $\boldsymbol{m}-\mathbf{3}$ in $\mathrm{CD}_{3} \mathrm{CN}$ at $348 \mathrm{~K}$.

the formation of aggregates that were about 100 times larger than the single triphenylene unit $\boldsymbol{m}-\mathbf{3}$. The 1:1 metal:ligand stoichiometry and the observation of these large aggregates suggested the formation of coordination polymers in solution. The latter experiments clearly demonstrated that the use of larger bite angle diphosphine ligands causes higher steric hindrance between the diphosphine ligand and the pyridine units of the triphenylene ligand, that eventually drives the formation of completely different assemblies. When less hindered ligated palladium(II) corners are used with $\boldsymbol{m}$-3, the expected triangular prism-shaped multiple complex is presumably obtained.

In order to prove this hypothesis, attempts to grow crystals from dichloromethane solutions of $\boldsymbol{m}-\mathbf{3}$ with 5 and $\mathbf{6}$ in a $\mathrm{M}_{3} \mathrm{~L}_{2}$ molar ratio were made. Unfortunately, the obtained crystals were not suitable for X-ray diffraction. Hence, several ESI-MS analyses were carried out both with dichloromethane and acetonitrile solutions, but no evidence of the formation stable polycationic cages in solution was observed. The main detected peaks corresponded to a $\mathrm{Pd}(\mathrm{II})$ metal center bearing the diphosphine, one triflate anion and one $\boldsymbol{m}$-3 ligand coordinated through one pyridine unit $(\mathrm{m} / \mathrm{z}$ 1600.93 and 1614.91 , corresponding to $[\operatorname{Pd}(\mathrm{dppe})(\boldsymbol{m}-3)(\mathrm{OTf})]^{+}$ and $[\operatorname{Pd}(\mathrm{dppp})(\boldsymbol{m}-\mathbf{3})(\mathrm{OTf})]^{+}$fragments). None of such peaks were detected with the $\mathrm{Pt}(\mathrm{II})$ metal corners. It is likely that the $\mathrm{M}_{3} \mathrm{~L}_{2}$ assembly cannot survive the de-solvation process in the ESI analysis because of the presence of several exchange equilibria in solution related to the chirality of the triphenylene units when coordinated and to steric interactions between the triphenylene units. This could explain the fact that mainly the $\left[\mathrm{M}_{1} \mathrm{~L}_{1} \mathrm{OTf}\right]^{+}$species was detected by mass spectrometry (see ESI).

As a final investigation on the formation of a $\mathrm{M}_{3} \mathrm{~L}_{2}$ coordination cage, we studied the coordination of the three tris-pyridine ligands $\mathbf{o -}, \boldsymbol{m}$ - and $\boldsymbol{p}-\mathbf{3}$ with a cis-square planar palladium(II) in silico [31]. The modeling process initially started by considering simplified structures in which the flexible benzyl moieties were removed to reduce the number of possible conformers, focusing on $\mathrm{M}_{3} \mathrm{~L}_{2}$ aggregates with cis-square planar palladium(II) with chloride in place of the diphosphine ligands (see ESI). Through this approach we determined the relative energies of the $C_{3}$-symmetric homo-chiral racemic cages and the $C_{3 \mathrm{~h}}$-symmetric hetero-chiral meso cages (confirming that the latter are characterized by higher energy), as well as different combinations of axial and equatorial conformations of the pyridine units in the di-hydro-oxazolinic moieties. This analysis confirmed that for the homo-chiral $\mathrm{M}_{3} \mathrm{~L}_{2}$ cages many isomeric structures with comparable energies could be present in equilibrium (see ESI). Finally, the dppp ligand (in both helical conformations) was substituted to the chloride ligands in the lower energy obtained structures for more stable homo-chiral $M_{3} L_{2}$

Table 1

Minimized energies (semi-empirical level PM6) for the simplified complexes of $\boldsymbol{o}, \boldsymbol{m}, \boldsymbol{p}$-3 (benzyl units omitted) and $\mathbf{5}$ (see ESI for details).

\begin{tabular}{|c|c|c|c|c|}
\hline Cage & Enantio-topic faces & Amine-pyridine conformer & Helicity of dppe & Rel. Energy Kcal/mol \\
\hline $\operatorname{cis}-\left[\mathbf{5}_{3}(\mathbf{o - 3})_{2}\right]$ & $R R / S S$ & $a x-a x$ & $P$ & 140.4 \\
\hline $\operatorname{cis}-\left[\mathbf{5}_{3}(\mathbf{o - 3})_{2}\right]$ & $R R / S S$ & $e q-e q$ & $M$ & 131.4 \\
\hline $\operatorname{cis}-\left[\mathbf{5}_{3}(\boldsymbol{m}-\mathbf{3})_{2}\right]$ & $R R / S S$ & $a x-a x$ & $P$ & 66.2 \\
\hline $\operatorname{cis}-\left[\mathbf{5}_{3}(\boldsymbol{m}-\mathbf{3})_{2}\right]$ & $R R / S S$ & $a x-e q$ & $M$ & 0.0 \\
\hline $\operatorname{cis}-\left[\mathbf{5}_{3}(\boldsymbol{p}-\mathbf{3})_{2}\right]$ & $R R / S S$ & $a x-a x$ & $P$ & 36.4 \\
\hline $\operatorname{cis}-\left[\mathbf{5}_{3}(\boldsymbol{p}-\mathbf{3})_{2}\right]$ & $R R / S S$ & $e q-e q$ & $M$ & 32.6 \\
\hline
\end{tabular}




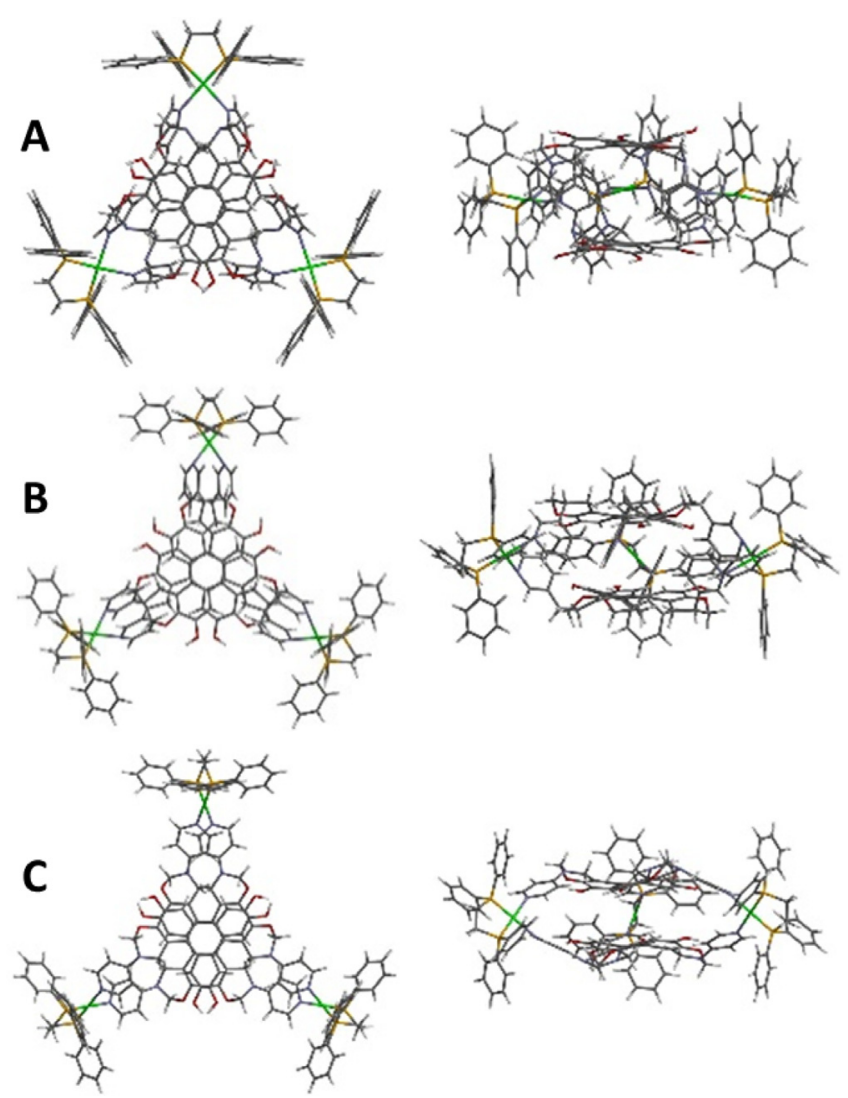

Fig. 8. Top and side view for the minimized (benzyl-omitted) $\mathrm{M}_{3} \mathrm{~L}_{2}$ cages for (a) cis$\left[\mathbf{5}_{3}(\boldsymbol{o}-\mathbf{3})_{2}\right],(\mathrm{b})$ cis- $\left[\mathbf{5}_{3}(\boldsymbol{m}-\mathbf{3})_{2}\right]$ and (c) cis- $\left[\mathbf{5}_{3}(\boldsymbol{p}-\mathbf{3})_{2}\right]$.

assemblies (Table 1 and Fig. 8). According to these calculations, the more stable complex was observed with ligand $\boldsymbol{m}-\mathbf{3}$ (in particular with $M$ helicity of the dppe ligands and ax-eq conformation of the amine pyridine units). This computational result agreed with the experimental observation of a clear solution and a well-defined $\mathrm{M}_{3} \mathrm{~L}_{2}$ stoichiometry in different solvents as well as pseudo 2DDOSY experiments with a diffusion coefficient for the cage that was lower but still comparable to that of the free ligand. The calculations further supported the experimental observation of the broadening of the resonances observed in the ${ }^{1} \mathrm{H}$ NMR spectra likely due to exchange processes between the different conformers of the pyridine and the diphosphane units.

\section{Conclusion}

In conclusion, herein we report the efficient synthesis of three $C_{3}$-symmetric triphenylene tridentate pyridine ligands for the synthesis of coordination cages in solution with $\mathrm{Pd}(\mathrm{II})$ or Pt(II) metal centers as coordination corners. Among the three ligands considered, $\boldsymbol{m}-\mathbf{3}$ provided in solution the formation of a $\mathrm{M}_{3} \mathrm{~L}_{2}$ cage both with the Pd(II) or Pt(II) metal center when using dppe as a ligand for the metal. In contrast, the o-3 ligand led to more unstable assemblies and $\boldsymbol{p}-\mathbf{3}$ ligands led only to the formation of coordination polymers that eventually precipitated from the solution, regardless the use of $\mathrm{Pd}(\mathrm{II})$ or $\mathrm{Pt}(\mathrm{II})$ metal centers. As far as the $\boldsymbol{m}$-3 ligand is concerned, ${ }^{1} \mathrm{H}$ NMR pseudo-2D-DOSY experiments and ${ }^{19} \mathrm{~F}$ NMR titrations demonstrated the formation of clear $\mathrm{M}_{3} \mathrm{~L}_{2}$ aggregates in solution, even though the ${ }^{31} \mathrm{P}$ NMR and ${ }^{1} \mathrm{H}$ NMR spectra were not informative due to exchange processes. The latter were attributed to the formation of diastereoisomeric cages derived by the prochiral nature of the tris-pyridine triphenylene ligand once coordinated forming the trigonal bipyramidal unit and conformational equilibria of the ligand itself and of the diphosphane, as supported by quanto-mechanical calculations. No clearcut evidence of guest binding was observed due to the dynamic properties of the assemblies, although it cannot be excluded that in the narrow cavity, in particular for the cages formed with $\mathbf{o - 3}$ and $\boldsymbol{m}-\mathbf{3}$, binding of solvent molecules or more probably of counter-anions could occur.

\section{Declaration of Competing Interest}

The authors declare that they have no known competing financial interests or personal relationships that could have appeared to influence the work reported in this paper.

\section{Acknowledgements}

The authors acknowledge Università Ca' Foscari and MIUR for support.

\section{Appendix A. Supplementary data}

Supplementary data (detailed experimental procedures, full characterization and NMR spectra for the titration experiments, images and description of the minimized structures) to this article can be found online at https://doi.org/10.1016/j.tetlet.2019. 151202.

\section{References}

[1] R. Chakrabarty, P.S. Mukherjee, P.J. Stang, Chem. Rev. 111 (2011) 6810-6918.

[2] A. Schmidt, A. Casini, F.E. Kühn, Coord. Chem. Rev. 275 (2014) 19-36.

[3] L. Chen, Q. Chen, M. Wu, F. Jiang, M. Hong, Acc. Chem. Res. 48 (2015) 201-210.

[4] (a) L.-J. Chen, H.-B. Yang, M. Shionoya, Chem. Soc. Rev. 46 (2017) 2555;

(b) W.M. Bloch, G.H. Clever, Chem. Commun. 53 (2017) 8506;

(c) M.D. Ward, C.A. Hunter, N.H. Williams, Chem. Lett. 46 (2017) 2;

(d) R.A.S. Vasdev, D. Preston, J.D. Crowley, Chem. Asian J. 12 (2017) 2513;

(e) J.J. Henkelis, M.J. Hardie, Chem. Commun. 51 (2015) 11929;

(f) S. Zarra, D.M. Wood, D.A. Roberts, J.R. Nitschke, Chem. Soc. Rev. 44 (2015) 419;

(g) T.R. Cook, Y.-R. Zheng, P.J. Stang, Chem. Rev. 113 (2013) 734.

[5] A.J. Metherell, M.D. Ward, Dalton Trans. 45 (2016) 16096-16111.

[6] L.R. Holloway, P.M. Bogie, R.J. Hooley, Dalton Trans, 46 (2017) 14719-14723.

[7] A. Galana, P. Ballester, Chem. Soc. Rev. 45 (2016) 1720-1737.

[8] (a) S. Horiuchi, T. Murase, M. Fujita, J. Am. Chem. Soc. 133 (2011) 12445 12447;

(b) P. Mal, B. Breiner, K. Rissanen, J.R. Nitschke, Science 324 (2009) 1697 1699;

(c) J.L. Brumaghim, M. Michels, D. Pagliero, K.N. Raymond, Eur. J. Org. Chem. (2004) 5115-5118;

(d) J.L. Brumaghim, M. Michels, K.N. Raymond, Eur. J. Org. Chem. (2004) 45524559;

(e) M. Yamashina, Y. Sei, M. Akita, M. Yoshizawa, Nature Commun. 5 (2014) 5179.

[9] N. Ahmad, H.A. Younus, A.H. Chughtai, F. Verpoort, Chem. Soc. Rev. 44 (2015) 9-25.

[10] A. Ahmedova, Front. Chem. 6 (2018) 620.

[11] F.J. Rizzuto, L.K.S. von Krbek, J.R. Nitschke, Nature Rev. Chem. 3 (2019) $204-$ 222.

[12] M.D. Ward, C.A. Hunter, N.H. Williams, Chem. Lett. 46 (2017) 2-9.

[13] W.-X. Gao, H.-N. Zhang, G.-X. Jin, Coord. Chem. Rev. 386 (2019) 69-84.

[14] C. Tan, D. Chu, X. Tang, Y. Liu, W. Xuan, Y. Cui, Chem. Eur. J. 25 (2019) 662-672.

[15] C.M. Hong, R.G. Bergman, K.N. Raymond, F.D. Toste, Acc. Chem. Res. 51 (2018) 2447-2455.

[16] C.J. Hastings, R.G. Bergman, K.N. Raymond, J. Am. Chem. Soc. 132 (2010) 69386940.

[17] M. Yoshizawa, J.K. Klosterman, M. Fujita, Angew. Chem. Int. Ed. 48 (2009) 3418-3438.

[18] Y. Ueda, H. Ito, D. Fujita, M. Fujita, J. Am. Chem. Soc. 139 (2017) 6090-6093.

[19] (a) S. Gonell, X. Caumes, N. Orth, I. Ivanović-Burmazović, J.N.H. Reek, Chem. Sci. 10 (2019) 1316-1321;

(b) S. Gonell, J.N.H. Reek, ChemCatChem 11 (2019) 1458-1464.

[20] (a) D. Zhang, T.K. Ronson, J.R. Nitschke, Acc. Chem. Res. 51 (2018) 2423-2436; (b) E.G. Percástegui, J. Mosquera, T.K. Ronson, A.J. Plajer, M. Kieffer, J.R Nitschke, Chem. Sci. 10 (2019) 2006-2018.

[21] M.D. Ward, C.A. Hunter, N.H. Williams, Acc. Chem. Res. 51 (2018) 2073-2082.

[22] S. Durot, J. Taesch, V. Heitz, Chem. Rev. 114 (2014) 8542-8578. 
[23] M. Han, D.M. Engelhard, G.H. Clever, Chem. Soc. Rev. 43 (2014) 1848-1860.

[24] R. Custelcean, Chem. Soc. Rev. 43 (2014) 1813-1824.

[25] G. Berton, G. Borsato, R. Zangrando, A. Gambaro, F. Fabris, A. Scarso, Org. Chem. Front. 5 (2018) 2458-2462.

[26] (a) Selected examples of $\mathrm{M}_{3} \mathrm{~L}_{2}$ cages: C.G. Claessens, T. Torres Chem. Commun. (2004) 1298-1299;

(b) M. Wang, V. Vajpayee, S. Shanmugaraju, Y.-R. Zheng, Z. Zhao, H. Kim, P. Sarathi Mukherjee, K.-W. Chi, P.J. Stang, Inorg. Chem. 50 (2011) 1506-1512;

(c) S. Tartaggia, O. De Lucchi, A. Gambaro, R. Zangrando, F. Fabris, A. Scarso, Chem. Eur. J. 19 (2013) 5701-5714;

(d) S. Oldknow, D. Rota Martir, V.E. Pritchard, M.A. Blitz, C.W.G. Fishwick, E. Zysman-Colman, M.J. Hardie, Chem. Sci. 9 (2018) 8150-8159;

(e) Y. Imai, J. Yuasa, Chem. Sci. 10 (2019) 4236-4245;

(f) Q. Chen, L. Chen, F. Jiang, M. Hong, Chem. Rec. 15 (2015) 711-727;

(g) J. Fan, W.-Y. Sun, T.-aki Okamura, J. Xie, W.-X. Tang, N. Ueyama, New J. Chem. 26 (2002) 199-201;

(h) D. Kumar Chand, M. Fujita, K. Biradha, S. Sakamoto, K. Yamaguchi, Dalton Trans. (2003) 2750-2756;

(i) B. Brusilowskij, S. Neubacher, C.A. Schalley, Chem. Commun. (2009) 785787; (j) J.J. Henkelis, T.K. Ronson, L.P. Harding, M.J. Hardie, Chem. Commun. 47 (2011) 6560-6562:

(k) C.G. Claessens, T. Torres, J. Am. Chem. Soc. 124 (2002) 14522-14523;

(1) C.G. Claessens, I. Sànchez-Molina, T. Torres, Supram. Chem. 21 (2009) 4447.

(m) H.-B. Yang, K. Ghosh, N. Das, P.J. Stang, Org. Lett. 8 (2006) 3991-3994;

(n) H.-B. Yang, K. Ghosh, A.M. Arif, P.J. Stang, J. Org. Chem. 71 (2006) 94649469.

[27] A. Schmidt, M. Hollering, J. Han, A. Casin, F.E. Kühn, Dalton Trans. 45 (2016) $12297-12300$.

[28] G.T.L. Broadwood-Strong, P.A. Chaloner, P.B. Mitchcock, Polyhedron 12 (1993) $721-729$

[29] S.J. Sabounchei, M. Ahmadi, Z. Nasri, E. Shams, S.J. Sabounchei, M. Ahmadi, Z. Nasri, E. Shams, C. R. Chimie 16 (2013) 159-175.

[30] A. Macchioni, G. Ciancaleoni, C. Zuccaccia, D. Zuccaccia, Chem. Soc. Rev. 37 (2007) 479-489.

[31] Structures were minimized at the semi-empirical level (PM6) with MOPAC2016, Version: 19.179W, James J. P. Stewart, Stewart Computational Chemistry, http://OpenMOPAC.net. J.J.P. Stewart J. Mol. Mod. 13 (2007) 11731213. 